\title{
AI Startup Business Models
}

\section{Key Characteristics and Directions for Entrepreneurship Research}

\author{
Michael Weber $(\mathbb{D} \cdot$ Moritz Beutter $(\mathbb{D} \cdot$ Jörg Weking $(\mathbb{D} \cdot$ Markus Böhm $\mathbb{D}$ • \\ Helmut KrcmariD
}

Received: 10 March 2021 / Accepted: 18 October 2021/Published online: 13 December 2021

(C) The Author(s) 2021

\begin{abstract}
We currently observe the rapid emergence of startups that use Artificial Intelligence (AI) as part of their business model. While recent research suggests that AI startups employ novel or different business models, one could argue that AI technology has been used in business models for a long time already - questioning the novelty of those business models. Therefore, this study investigates how AI startup business models potentially differ from common IT-related business models. First, a business model taxonomy of AI startups is developed from a sample of 100 AI startups and four archetypal business model patterns are derived: AI-charged Product/Service Provider, AI Development Facilitator, Data Analytics Provider, and Deep Tech Researcher. Second, drawing on this descriptive analysis, three distinctive aspects of AI startup business models are discussed: (1) new value propositions through AI capabilities, (2) different roles of data for value creation, and (3) the impact of AI technology on the overall
\end{abstract}

Accepted after three revisions by the editors of the special issue.

M. Weber $(\bowtie) \cdot$ M. Beutter · J. Weking $\cdot$ H. Krcmar

Technische Universität München, Boltzmannstr. 3,

85748 Garching, Germany

e-mail: mic.weber@tum.de

M. Beutter

e-mail: moritz.beutter@tum.de

J. Weking

e-mail: joerg.weking@tum.de

H. Kremar

e-mail: helmut.krcmar@tum.de

M. Böhm

University of Applied Sciences Landshut, Am Lurzenhof 1,

84036 Landshut, Germany

e-mail: markus.boehm@haw-landshut.de business logic. This study contributes to our fundamental understanding of AI startup business models by identifying their key characteristics, common instantiations, and distinctive aspects. Furthermore, this study proposes promising directions for future entrepreneurship research. For practice, the taxonomy and patterns serve as structured tools to support entrepreneurial action.

Keywords Artificial intelligence · Machine learning · Entrepreneurship · Business model · Taxonomy · Pattern

\section{Introduction}

Artificial Intelligence (AI) inarguably creates large waves of excitement in business and research alike. AI refers to a broad suite of techniques (Russell and Norvig 2016) that gives machines the ability "to perform cognitive functions that we associate with human minds, such as perceiving, reasoning, learning, $[\ldots]$ and even demonstrating creativity" (Rai et al. 2019, p. iii). AI technology might serve as an external enabler (Davidsson et al. 2020) that offers manifold opportunities for entrepreneurship (Chalmers et al. 2020; Obschonka and Audretsch 2020). Indeed, we can observe the rapid emergence of AI startups that apply AI technology as a key element to their product or service. For instance, the database Crunchbase (https://www. crunchbase.com) lists over 27,900 startups related to "Artificial Intelligence" as of September 2021. Popular examples include the research-driven venture OpenAI or the business automation venture UiPath. Those AI startups attract a significant and growing interest of investors and venture capital firms, as evident in the staggering amount of investment into AI startups (OECD 2018) and the perceived frequency of intriguing news headlines (e.g., 
Microsoft's $\$ 19.7$ billion acquisition of health AI company Nuance (Wilhelm and Heim 2021)).

Regardless of the current hype, it will be indispensable for those startups to find an appropriate business model to ensure their long-term performance and survival (George and Bock 2011; Böhm et al. 2017). The business model represents the focal business logic of a firm (Teece 2010) and is essential to the successful commercialization of any technology (Chesbrough 2010). Recent research suggests that AI startups employ novel or different business models. Economists have predicted that the use of AI technology and its unique capabilities will lead to new products, services, and business models (Brynjolfsson and McAfee 2017; Makridakis 2017). Furthermore, Information Systems (IS) scholars have noted significant challenges to the successful value creation from AI (Jöhnk et al. 2021; Benbya et al. 2020). Hence, different key activities and partnerships might be required in the business model. However, one could also argue that AI technology is not new (Stone et al. 2016) and has been used in business models for a long time already, which questions the novelty of AI startup business models. For example, while data is essential to the value creation from AI (Jöhnk et al. 2021), the use of data in business models has long been recognized in research (e.g., Hartmann et al. 2016). Moreover, many business models, such as those of digital platform providers (Hein et al. 2020), have already implicitly used AI technology at the core of their business (Gregory et al. 2020). Hence, the question arises whether AI startups employ novel or different business models, and if so, how they differ from common IT-related business models.

Clarifying these potential differences would contribute to our fundamental understanding of AI startup business models. A fundamental understanding of a phenomenon is essential for any research stream to support theory development and testing (Gregor 2006; Rich 1992). For example, a descriptive analysis of AI startup business models would help to structure the diverse landscape of AI startups and reveal a clear set of categories that can further be studied. It would also provide insights into how AI, a different technology to traditional IT (Ågerfalk 2020; Berente et al. 2021), impacts startup business models in ways that potentially challenge our current theoretical underpinnings. In addition, a fundamental understanding of AI startup business models is highly relevant for practitioners, for example, when developing new business models using AI technology, or when evaluating and investing in AI startups.

However, extant research on AI startup business models is in its infancy, and studies investigating AI-related business models are scarce (e.g., Garbuio and Lin 2019; Armour and Sako 2020). Hence, our current understanding of the characteristics of AI startup business models is limited; and the question of what potentially differentiates them from common IT-related business models remains to be answered. Consequently, more research on AI startup business models is considered a priority for the field (Obschonka and Audretsch 2020). To address this gap, we ask the research question: What are the differences between AI startup business models and common IT-related business models?

To examine this research question, we (1) identify the key characteristics of AI startup business models and (2) distill the distinctive aspects against the background of prior research on IT-related business models. To that end, we first build a business model taxonomy for AI startups following the taxonomy development method proposed by Nickerson et al. (2013). Such an analytical approach is particularly valuable for novel and unstructured phenomena (Gregor 2006), such as AI startup business models. To develop the taxonomy, we build a case base of $100 \mathrm{AI}$ startups randomly drawn from Crunchbase, a database for startups, which we further triangulate with other data sources (Yin 2017). In an iterative development process, we combine empirical findings from our sample of $100 \mathrm{AI}$ startups with prior theoretical concepts from literature. The taxonomy of AI startups follows the conceptual representation of a business model (Massa et al. 2017). We further apply the resulting taxonomy to the sample of $100 \mathrm{AI}$ startups and perform a hierarchical cluster analysis to derive four archetypal business model patterns. These patterns represent common instantiations of AI startup business models in practice. Against the background of prior studies on IT-related business models, we ultimately discuss the distinctive aspects of AI startup business models and propose directions for future entrepreneurship research.

We contribute to a growing research stream concerned with AI in entrepreneurship (Chalmers et al. 2020; Obschonka and Audretsch 2020) and research on IT-related business models (Veit et al. 2014; Steininger 2019). First, we address how AI startup business models differ from common IT-related business models to shed light on the impact of AI technology on startup business models. Second, our descriptive analysis allows us to derive promising directions for future research on AI in entrepreneurship. Third, we provide one of the first comprehensive analyses of AI startup business models. Our taxonomy and patterns reveal the key characteristics of AI startup business models and their common instantiations, which can serve as a springboard for future research. As Rich (1992, p. 758) put it, "organizational classification provides the basis for strong research by breaking the continuous world of organizations into discrete and collective categories well suited for detailed analysis." For practice, the taxonomy 
and patterns can be used as structured tools to support venture creation and business model innovation using AI technology. Moreover, they provide insights into a complex and diverse AI startup landscape, assisting investors and venture capitalists in their activities.

\section{Background}

The background section of this study is threefold: First, we clarify the term "Artificial Intelligence" and describe recent developments. Second, we take a closer look at research on IT-related business models and highlight imporant findings in this area. Third, we present related work that has investigated the influence of AI technology on business models.

\subsection{Artificial Intelligence}

AI refers to a broad and long-established research field in computer science (Stone et al. 2016). The AI research field never had a clear definition, but rather had the creation of intelligent machines as a common goal in mind (Stone et al. 2016). Machine intelligence can be interpreted as machines thinking or acting rational, or thinking or acting like humans (Russell and Norvig 2016). Therefore, it is typically associated with machines performing functions such as perceiving, learning, reasoning, problem-solving, and demonstrating creativity (Rai et al. 2019). Throughout the years, AI researchers have developed a plethora of techniques and methods, including machine learning, deep learning, knowledge-based reasoning, natural language processing (NLP), computer vision, and robotics (Stone et al. 2016). We summarize these under the term AI technology. In recent years, AI has gained renewed momentum thanks to advances in machine learning, computational processing, and the vast availability of data (Ågerfalk 2020; Berente et al. 2021; Haenlein and Kaplan 2019). Machine learning is an AI technology that enables machines to improve automatically through experience, which is often accomplished by analyzing patterns in existing data (Jordan and Mitchell 2015). Thereby, an information system is basically able to create its own rules (Aggerfalk 2020). An important subset of machine learning is deep learning, which uses multiple processing layers to learn from data at multiple levels of abstraction (LeCun et al. 2015). Recent breakthroughs in deep learning have caused significant improvements in many areas of AI including speech recognition, object detection, and medical drug discovery (LeCun et al. 2015).

\subsection{IT-related Business Models}

When using the term business model, we refer to the conceptual representation of a business model, as suggested to clarify by Massa et al. (2017). Various definitions for the business model have emerged over time (Wirtz et al. 2016). Above all, the business model describes the business logic of a firm (Teece 2010). It describes the value proposition that is offered, how the value is created and delivered to the customers, and how revenue is generated and captured (Teece 2010). The business model is often conceptualized by its constituting components or building blocks, for example, the customer segment or the revenue stream (Remane et al. 2017; Osterwalder and Pigneur 2010). In IS research, the business model is considered the missing link between strategy, processes, and IT (Veit et al. 2014). Therefore, it is widely used as a lens to study how IT alters existing and creates new business models, including those of startups (e.g., Spiegel et al. 2016; Hartmann et al. 2016). Following the framework proposed by Steininger (2019), IT can facilitate the operations of startups, serve as mediator at the customer interface, and be the product or service itself. In this study, we investigated startups that use AI technology as a core component of the offered product or service.

Prior research investigated IT-related business models in various contexts and found a plethora of ways IT can alter existing and enable new business models (Veit et al. 2014; Bock and Wiener 2017). Examples include the servitization of industrial products using the Internet of Things (Weking et al. 2020c), the disintermediation of transactions through distributed ledgers (Chong et al. 2019), or the creation of multi-sided digital platforms (Täuscher and Laudien 2018; Floetgen et al. 2021). Within IT-related business model research, one stream is concerned with data-driven business models (Wiener et al. 2020). As AI, big data, and analytics can be seen as "three different, although related beasts” (Ågerfalk 2020, p. 2), we expect to find overlapping characteristics regarding the business model. Wiener et al. (2020) distinguish three archetypes of business models: data users, data suppliers, and data facilitators. Data users use big data to streamline their operations or to create new products or services. Data suppliers collect and sell data to other firms. Data facilitators enable other firms to use big data analytics, for example by providing the necessary infrastructure or analytics as a service (Hartmann et al. 2016). We will later discuss how AI startup business models potentially differ from common IT-related business models. 
2.3 Related Work on Artificial Intelligence and Business Models

Extant research linking AI with the business model concept has predominately focused on the impact of AI technology on internal processes of value creation. As such, AI can be used to automate operations, create insights for decisionmaking, and provide new means for engaging with customers and employees (Davenport and Ronanki 2018; Borges et al. 2021). For example, in the legal industry AI technology can increase the efficiency of operations by taking over routine tasks and assisting humans with nonroutine tasks (Armour and Sako 2020). Here, especially the use of NLP is expected to play a major role, because it enables the automated analysis of documents (Brooks et al. 2020). As another example, in the healthcare industry AI technology is used to increase the quality of services, for example, supporting the detection of diseases like cancer (Valter et al. 2018). In contrast, Canhoto and Clear (2020) point to novel risks introduced into the business model when using AI technology. For example, value creation might be negatively influenced when AI solutions make wrong or biased decisions.

In addition to its impact on operations, AI technology can enable new products and services (Davenport et al. 2020; Borges et al. 2021). However, following Borges et al. (2021), we found that extant research thus far lacks a thorough examination of AI technology's potential to enable new products and services. Specifically, research on the underlying business models used to commercialize these products and services is scarce. Therefore, Garbuio and Lin (2019) conducted a comprehensive study of AI startups in the healthcare industry as a rare example. They found that AI startups target multiple value areas, including solutions for patient lifestyle management, patient safety, or operational efficiency of healthcare providers (Garbuio and Lin 2019). They distinguish between two business model archetypes: startups that provide information and startups that aim at connecting multiple parties. Furthermore, they identified three delivery models employed by AI startups: the platform model (or multisided market business model), software as a service, and platform as a service (Garbuio and Lin 2019). In their study on the industrial Internet of Things, Ehret and Wirtz (2017) recognize the potential to offer new services in combination with AI technology, for example, using sensor data for predictive maintenance. Hence, traditional business models involving physical machines are complemented with databased analyses to create new value propositions.

In conclusion, research has just started to investigate AIrelated business models. Much focus has been put on AI technology's potential to enhance internal operations. In contrast, business models with AI technology as a core component of the product or service remain mostly unstudied. Therefore, we currently do not know how the business models employed by AI startups potentially differ from common IT-related business models. However, this would contribute to our fundamental understanding of AI startup business models. Therefore, we address this research question in this study.

\section{Research Method}

To address our research question, we (1) identify the key characteristics of AI startup business models and (2) distill the distinctive aspects against the background of prior research on common IT-related business models. First, we build a case base containing 100 AI startups (Yin 2017). Second, we develop a business model taxonomy of AI startups using the method proposed by Nickerson et al. (2013), which reveals the key characteristics of AI startup business models (cf. Sect. 4.1). Third, we perform a hierarchical cluster analysis to derive four archetypal business model patterns, which gives us additional insights into common instantiations of AI startup business models (cf. Sect. 4.2). Against the background of extant research on IT-related business models, we ultimately distill the distinctive aspects of AI startup business models and provide directions for entrepreneurship research (cf. Sect. 5).

\subsection{Building a Case Base}

To gain empirical insights into the subject of our research, we created a case base of AI startups (Yin 2017). We used Crunchbase to identify the startups, because it is one of the world's largest databases of new ventures. Crunchbase has been widely used in research and serves as a valuable source to identify startups (e.g., Spiegel et al. 2016; Weking et al. 2020b). On 22 October 2020, we extracted all startups from Crunchbase that used the terms "Artificial Intelligence" or "Machine Learning" in their description. We found that other AI technologies such as deep learning, NLP, computer vision, and robotics were also covered with these terms. Using four selection criteria, we reduced the sample to startups aligned with the purpose of our research question (cf. Table 1). We filtered for startups that have a stable operating status and received over 1 million USD funding. This threshold was found useful after initial data exploration, because it eliminated many startups from the sample that had underdeveloped products or services, unclear and unestablished business models, or were already dead. In addition, we filtered for startups founded after 2010, as we wanted to include startups founded during the recent uptake of AI technology (Haenlein and Kaplan 2019). This initially led to a sample of 8076 AI-associated 
Table 1 Startup selection criteria

\begin{tabular}{|c|c|c|}
\hline Subject & Criteria & Rationale \\
\hline $\begin{array}{l}\text { Operating } \\
\text { status }\end{array}$ & $\begin{array}{l}\text { Not in financial distress and total secured funding exceeding } \\
\$ 1 \text { million }\end{array}$ & $\begin{array}{l}\text { Ensure that sample includes established startups with a defined } \\
\text { business model }\end{array}$ \\
\hline $\begin{array}{l}\text { Founding } \\
\text { year }\end{array}$ & After 2010 & $\begin{array}{l}\text { Reduce sample to contemporary startups; in line with recent rise } \\
\text { of AI technology }\end{array}$ \\
\hline Website & Accessible and available in English or German & $\begin{array}{l}\text { Ensure sufficient information for correct classification of the } \\
\text { startup }\end{array}$ \\
\hline $\begin{array}{l}\text { Business } \\
\text { model }\end{array}$ & AI technology as a core component of the product or service & Reduce sample to startups that align with research question \\
\hline
\end{tabular}

startups, which we imported into Microsoft Excel. From this sample, we randomly drew 100. For this, we used the random function of Microsoft Excel to generate a number between 1 and 8076. We validated the resulting startups in more detail for website and information availability. We then assessed whether AI technology was a core element of the business model. We only considered startups that use AI technology as a core component of their product or service, following the business model framework proposed by Steininger (2019). For every startup excluded at this stage, we redrew another startup until the case base contained a sample of 100 AI startups that meet all criteria. Table 5 in the Appendix shows the final list of startups considered in this study. We used multiple data sources to collect detailed information on each startup. Following Amshoff et al. (2015), we included (1) websites, (2) industry portals such as Crunchbase, (3) whitepapers, and (4) investment interviews. On average, we used 3.8 data sources per startup. The diversity of data sources allowed for data triangulation, which helps to address potential bias from one source (Yin 2017).

\subsection{Taxonomy Development}

We used the taxonomy development method proposed by Nickerson et al. (2013) to develop a business model taxonomy of AI startups. This method allowed us to systematically combine prior theoretical concepts with empirical insights from our case base. Furthermore, the application of this method reduces the likelihood of adopting arbitrary dimensions and aims to increase the usefulness of the resulting taxonomy (Nickerson et al. 2013). This method has been widely used in IS research before, for example, to develop other business model taxonomies (e.g., Remane et al. 2017; Weking et al. 2020b).

The first step of the method is to define the meta-characteristic, which should be "the most comprehensive characteristic that will serve as the basis for the choice of characteristics in the taxonomy" (Nickerson et al. 2013, p. 343). To classify AI startups, we used the conceptual representation of a business model (Massa et al. 2017) as the meta-characteristic. Following that, we looked for any dimension or characteristic that describes an element of the business model of an AI startup, which includes the value proposition, value creation, value delivery, or value capture (Teece 2010; Gassmann et al. 2014). The second step comprises the definition of ending conditions for the taxonomy development. For this, we build on the objective and subjective ending conditions proposed by Nickerson et al. (2013). First, we must have considered a representative sample of AI startup business models. Second, we require the dimensions and characteristics of the taxonomy to be mutually exclusive and collectively exhaustive to describe AI startup business models. Third, every characteristic must at least occur once at an object from the sample. Fourth, no dimensions or characteristics must have been added, deleted, or modified during the last iteration of taxonomy development. Fifth, we add subjective ending conditions, in that we require the taxonomy to be concise, robust, comprehensive, extendible, and explanatory (Nickerson et al. 2013).

The next steps are to develop the taxonomy iteratively. Before every iteration, one must choose between the conceptual-to-empirical and the empirical-to-conceptual approach (Nickerson et al. 2013). The conceptual-to-empirical approach is recommended if the researchers are already familiar with the domain of interest. Building on our initial conceptual understanding, we first chose this approach to derive the initial dimensions and characteristics of the taxonomy. First, we added the dimensions of the business model canvas (Osterwalder and Pigneur 2010), namely key partners, key activities, key resources, customer relationships, channels, customer segments, cost structure, and revenue streams. The business model canvas is widely accepted in research, compromises the key dimensions of a business model, and is generally applicable to all contexts. Hence, it serves as a promising starting point to structure a new field of business models. Second, 
we added AI-related dimensions, namely data structure (Hartmann et al. 2016), data ownership (Hartmann et al. 2016), AI technology (Russell and Norvig 2016), and additional technology (Weking et al. 2020c). Using 25 startups from our case base, we examined and evaluated the conceptually derived dimensions and characteristics, which resulted in an initial taxonomy.

Following the first iteration, we further developed the taxonomy using the empirical-to-conceptual approach. This approach suggests deriving common characteristics from objects that are similar and can be grouped (Nickerson et al. 2013). For each iteration, we first drew a subset of AI startups from our case base. Two of the authors then independently analyzed, compared, and grouped the startups given the taxonomy. Next, we discussed and merged our findings to add, delete, or modify dimensions and characteristics. After each iteration, we checked the previously defined ending conditions, increased our sample of AI startups, and started the next iteration. After three additional iterations, this procedure resulted in adding, deleting, and modifying multiple dimensions and characteristics. Figure 1 outlines the development of dimensions for the taxonomy.

After the fourth iteration, we now considered all $100 \mathrm{AI}$ startups and again evaluated the taxonomy based on the previously defined ending conditions (Nickerson et al. 2013). The taxonomy was mutually exclusive and collectively exhaustive and allowed us to classify all $100 \mathrm{AI}$ startups from the sample. Each characteristic was attributed to at least one AI startup in the sample. Furthermore, we did not have to add, delete, or modify any of the dimensions and characteristics. This also suggested that we had analyzed a reasonably representative sample of AI startups. We further discussed whether the taxonomy was sufficiently concise, robust, comprehensive, extendible, and explanatory within the research team, which ultimately concluded in an affirmation. Therefore, all previously defined objective and subjective ending conditions were met and the taxonomy development terminated.

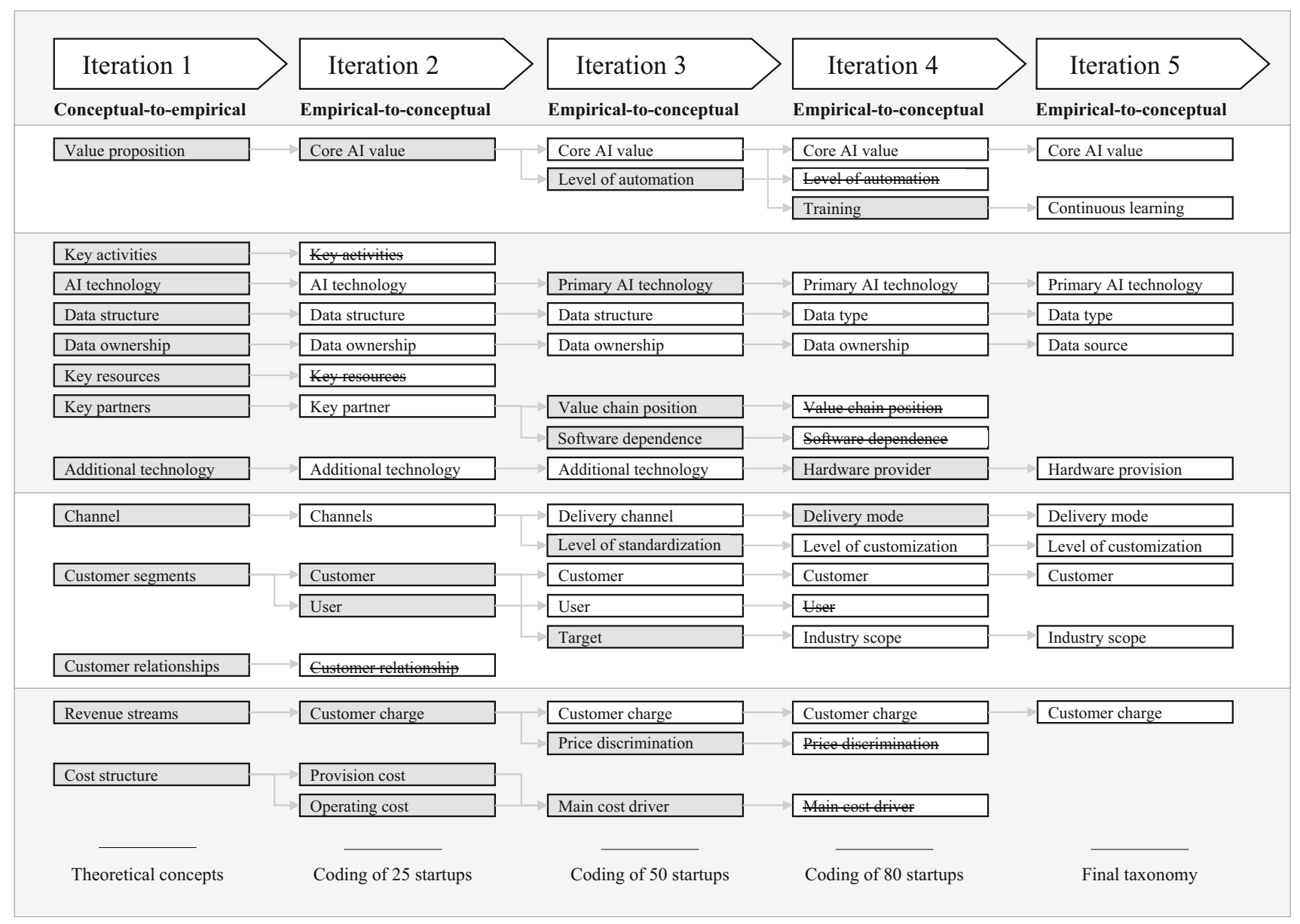

Fig. 1 Iterative development of dimensions for business model taxonomy (own illustration) 
3.3 Application of the Taxonomy and Pattern Development

We further applied the resulting taxonomy to derive business model patterns. Thereby, we go beyond the mere identification of key characteristics and reveal common instantiations of AI startup business models in practice. Patterns are popular artifacts in business model research (Remane et al. 2017; Weking et al. 2020a), because they represent an abstraction from proven real-world business models that is useful for both research and practice (Amshoff et al. 2015). For example, business model research could use such patterns to create a typology (Doty and Glick 1994) that links the patterns to certain outcomes (e.g., venture growth). In practice, business model patterns can be directly implemented to support business model innovation (Remane et al. 2017; Gassmann et al. 2014).

We performed a quantitative cluster analysis (Ketchen and Shook 1996) on our sample of 100 AI startups to derive the patterns. We followed the four steps proposed by Sarstedt and Mooi (2014) to perform the cluster analysis. First, we selected the variables used for clustering (Sarstedt and Mooi 2014). As an outcome of the taxonomy development process, we had already classified all 100 AI startups using the dimensions and characteristics of the taxonomy. We removed the dimensions continuous learning, data type, and customer charge, because we did not have enough reliable information consistently available for all startups. We then transformed the eight dimensions into dichotomous dummy variables. Second, we selected a clustering approach. We decided for hierarchical agglomerative clustering using the Ward method, because it allows for a stable analysis even for smaller sample sizes (Sarstedt and Mooi 2014). In addition, the Ward method is applicable when there is no information about the optimal cluster size. Third, after having applied the Ward method, we determined the number of clusters. We analyzed the distance where the objects are combined, which is a useful metric for deciding on the number of clusters (Sarstedt and Mooi 2014). We selected the cutoff at which the combination of clusters or objects would occur at a maximum distance. This procedure resulted in four clusters (Fig. 2). Table 5 in the Appendix shows the cluster assignment for each startup.

In the fourth step, we validated the clusters to ensure meaning and usefulness (Ketchen and Shook 1996). We first made sense of the resulting clusters by analyzing the absolute and relative occurrences of characteristics across clusters and calculating the standardized mean difference of the relative occurrences within one cluster compared to the total sample (cf. Table 6 in the Appendix, cf. Table A.1 in the online Appendix for full results). This allowed us to interpret and understand the respective business model pattern that each cluster potentially represents. Thereby, we could derive four business model patterns that from our perspective represent useful abstractions. Furthermore, we validated the performance of the clustering. We manually assigned all $100 \mathrm{AI}$ startups to the four clusters based on our qualitative assessment. We then compared our assignment with the result from Ward's method to test the logic and the applicability of the clustering. The assignment was correct in $84 \%$ of the cases. Thus, we could demonstrate external heterogeneities between the clusters and internal homogeneities. We conclude that the four clusters, and patterns respectively, are meaningful and valid.

\section{Results}

The results section of this study is twofold: First, we present the resulting business model taxonomy of AI startups and depict each dimension and characteristic in more detail. Second, we present the four archetypal business model patterns of AI startups and provide illustrative examples for each pattern.

\subsection{Business Model Taxonomy of AI Startups}

The resulting taxonomy consists of 11 dimensions and 39 characteristics and is based on the conceptual representation of a business model (Massa et al. 2017). Each combination of characteristics across the dimensions results in a new instantiation of an AI startup business model. The taxonomy is shown in Table 2. In the following, we will describe each dimension and characteristic in more detail.

Regarding value proposition, we found that AI startup business models can be classified by the two dimensions core AI value and continuous learning. First, the core AI value describes the value that is created by the respective AI solutions that AI startups employ as part of their product or service. We found that these solutions either aim to analyze vast amounts of data, including mostly unstructured data, to create cognitive insights, to analyze streams of data for monitoring \& anomaly detection, to provide interactive process \& task support for humans, or to automate tasks through autonomous robots \& bots. For example, the startup Zebrium analyzes log files of various platforms and detects anomalies in real-time. As another example, the startup Osaro offers industrial robots with computer vision to automate packaging tasks. Second, continuous learning describes whether or how the respective AI solutions are capable of learning from new data over time. Thereby, the respective AI solution might become more accurate over time as part of the value proposition. Whereas some AI solutions are improved at 


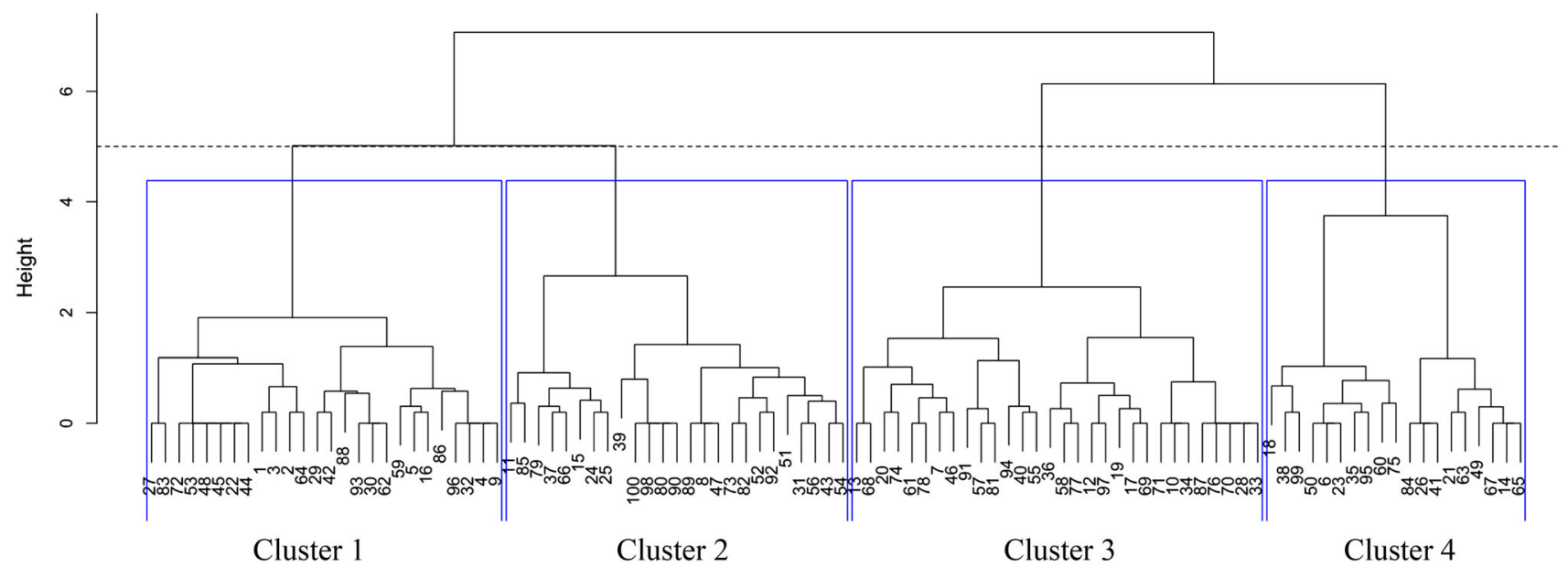

Fig. 2 Dendrogram with clustering results (own illustration, created with RStudio)

Table 2 Business model taxonomy of AI startups

\begin{tabular}{|c|c|c|c|c|c|c|}
\hline Category & Dimension & Characteristics & & & & \\
\hline \multirow[t]{2}{*}{$\begin{array}{l}\text { Value } \\
\text { proposition }\end{array}$} & Core AI value & Cognitive insights & $\begin{array}{l}\text { Monitoring \& } \\
\text { anomaly detection }\end{array}$ & $\begin{array}{l}\text { Process \& task } \\
\text { support }\end{array}$ & $\begin{array}{l}\text { Autonomous robots } \\
\& \text { bots }\end{array}$ & \\
\hline & $\begin{array}{l}\text { Continuous } \\
\text { learning }\end{array}$ & $\begin{array}{l}\text { Central learning \& } \\
\text { updates }\end{array}$ & $\begin{array}{l}\text { Learning at customer } \\
\text { side }\end{array}$ & Not provided & & \\
\hline \multirow[t]{4}{*}{$\begin{array}{l}\text { Value } \\
\text { creation }\end{array}$} & $\begin{array}{l}\text { Primary AI } \\
\text { technology }\end{array}$ & Machine learning & $\begin{array}{l}\text { Natural language } \\
\text { processing }\end{array}$ & $\begin{array}{l}\text { Computer } \\
\text { vision }\end{array}$ & Robotics & \\
\hline & Data type & $\begin{array}{l}\text { Numeric/sensor } \\
\text { data }\end{array}$ & $\begin{array}{l}\text { Textual/document } \\
\text { data }\end{array}$ & $\begin{array}{l}\text { Natural } \\
\text { language data }\end{array}$ & Visual data & Mixed data \\
\hline & Data source & Self-generated & Acquired & $\begin{array}{l}\text { Publicly } \\
\text { available }\end{array}$ & $\begin{array}{l}\text { Customer provided } \\
\text { on demand }\end{array}$ & $\begin{array}{l}\text { Customer transmitted } \\
\text { continuously }\end{array}$ \\
\hline & $\begin{array}{l}\text { Hardware } \\
\text { provision }\end{array}$ & Yes & No & & & \\
\hline \multirow[t]{4}{*}{$\begin{array}{l}\text { Value } \\
\text { delivery }\end{array}$} & Delivery mode & $\begin{array}{l}\text { Software } \\
\text { application }\end{array}$ & $\begin{array}{l}\text { Programmable } \\
\text { interface }\end{array}$ & $\begin{array}{l}\text { Base } \\
\text { technology }\end{array}$ & AI-produced output & \\
\hline & $\begin{array}{l}\text { Level of } \\
\text { customization }\end{array}$ & $\begin{array}{l}\text { Standardized } \\
\text { product/service }\end{array}$ & $\begin{array}{l}\text { Tailoring/ } \\
\text { Individualization }\end{array}$ & $\begin{array}{l}\text { Full } \\
\text { customization }\end{array}$ & & \\
\hline & Customer & B2B & B2C & Both & & \\
\hline & Industry scope & Industry focused & Industry agnostic & & & \\
\hline $\begin{array}{l}\text { Value } \\
\text { capture }\end{array}$ & $\begin{array}{l}\text { Customer } \\
\text { charge }\end{array}$ & Free of charge & Subscription-based & $\begin{array}{l}\text { Transaction- } \\
\text { based }\end{array}$ & One-time payment & \\
\hline
\end{tabular}

the provider side in the form of central learning \& updates to the customer base, other $\mathrm{AI}$ solutions are learning at the customer side without further interference by the provider. However, this feature is sometimes not provided by AI startups.

Regarding value proposition, we found that AI startup business models can be classified by four dimensions: primary AI technology, data type, data source, and hardware provision. First, primary AI technology describes the AI technology that is most essential to the startups' employed AI solution, both from a functional and marketing perspective. We can classify these AI technologies by "conventional" machine learning (includes shallow and deep machine learning for numerical or mixed data), natural language processing (includes analysis and generation of documents, texts, and speech), computer vision (includes analyses and generation of images and videos), and robotics (includes individual robotic components and autonomous vehicles). While the latter three types of AI technology typically rely on machine learning themselves, 
they also involve other or additional components that go beyond "conventional" machine learning, such as the lemmatization of textual data or sensors and actuators for robotics. Hence, we found this to be a meaningful and useful classification scheme. Second, the data type describes whether an AI startup predominately processes well-structured numeric/sensor data, textual/document data (excluding conversations), natural language data (including spoken language), visual data (including videos), or mixed data types. Third, the data source describes where the data used for training the AI solution originates from. Following prior research (e.g., Hartmann et al. 2016), we found that the data can either be selfgenerated at the startup side, be acquired from external data providers, collected from publicly available sources, or provided by the customer. In the latter case, we found a useful distinction between the data being customer provided on demand, or the data being customer transmitted continuously. For example, the startup SuperAnnotate uses batches of customer data that are provided on demand, whereas the startup Axonize offers a platform that constantly analyzes customer data. Fourth, hardware provision describes whether a startup also produces and offers specific hardware components as part of the business model, such as robotic components, drones, or cameras. For example, the startup Elemental Machines offers a data analytics platform and a broad range of sensors for data collection.

Regarding value delivery, we found that AI startup business models can be classified by four dimensions: delivery mode, level of customization, customer, and industry scope. First, the delivery mode describes how the value is delivered to the customer. Startups either offer software applications in diverse formats (e.g., web, desktop, mobile; on-premise, software-as-a-service), programmable interfaces on the code level (e.g., application programmable interfaces, software development kits, platform-as-a-service), or simply the base technology without having a software application or programmable interfaces (e.g., code pieces and specific algorithms). For example, the startup Hugging Face offers rich application programmable interfaces for NLP. In contrast, some startups do not provide software or hardware to their customers; but, instead, they solely provide the AI-produced output. For example, the startup Cyclica does not offer its technology directly to its customers. Instead, they provide AI-produced outputs for new drug discovery. Second, the level of customization describes how the startups' product or service can be configured and tailored to serve individual customer needs. Startups either deliver standardized products/services without further customization, the option for tailoring/individualization through parameterization or custom model training, or the option for full customization (e.g., in the case of fully programmable interfaces). Third, the customer describes whether the startups' product or service is targeted and sold to business customers $(B 2 B)$, private consumers $(B 2 C)$, or both. Fourth, the industry scope describes whether the startups' product or service is bound to a specific industry (industry focused), or whether it addresses customer needs across industries (industry agnostic). For example, the startup Notable provides a solution for the healthcare context, whereas the startup Wisdom AI is offering a customer service solution that can be used across industries.

Regarding value capture, we found that AI startup business models can be classified by the dimension customer charge. AI startups either offer their products and services free of charge, as part of a subscription-based or transaction-based model, or as a one-time payment. For example, the startup Fakespot provides a plugin that is free of charge, whereas the startup Kubit offers diverse subscription plans for their solution.

\subsection{Archetypal Business Model Patterns of AI Startups}

We identified four archetypal business model patterns of AI startups (Table 3). All 100 AI startups of our sample can be assigned to one of the patterns. The salient characteristics that define the patterns can be taken from Table 6 . These are the characteristics that make a pattern unique and different from other patterns. Based on these salient characteristics, we now describe each pattern in more detail, and provide illustrative examples of real-world AI startups from the sample.

Pattern 1: AI-charged Product/Service Provider Startups applying this pattern offer products or services with readily trained AI models embedded at the core of their business models. The solutions are mostly delivered as standardized products and services that do not require further customization. Startups of this pattern typically do not cover entire workflows, but offer a solution for one specific task case within an industry, for example, detecting forbidden items at airports (e.g., Synapse Technologies). The solutions are mainly sold to other business customers. Because the products and services are rather standardized, startups in this pattern are also able to serve private consumer needs in some instances. An example of this pattern is the startup Overjet. The solution allows dentists to upload X-ray images of a jaw and check them for malposition. Overjet enables a faster analysis for doctors and patients and ensures a more objective cost claim for insurance companies. Another example is Alegion, which offers a software service that supports manual data labeling by suggesting salient image sections in videos.

Pattern 2: AI Development Facilitator Startups applying this pattern focus on facilitating AI development for their 
Table 3 Archetypal business model patterns of AI startups

\begin{tabular}{|c|c|c|c|c|}
\hline Cluster & Pattern & Definition & $\begin{array}{l}\text { No. of } \\
\text { startups }\end{array}$ & Example startup \\
\hline 1 & $\begin{array}{l}\text { AI-charged } \\
\text { Product/Service } \\
\text { Provider }\end{array}$ & $\begin{array}{l}\text { Provide products and services that have readily } \\
\text { trained AI models embedded }\end{array}$ & 26 & $\begin{array}{l}\text { Alegion: Provides an AI-charged service that supports } \\
\text { manual data labelling }\end{array}$ \\
\hline 2 & $\begin{array}{l}\text { AI Development } \\
\text { Facilitator }\end{array}$ & $\begin{array}{l}\text { Facilitate AI development of customers with } \\
\text { customizable solutions or technical interfaces }\end{array}$ & 25 & $\begin{array}{l}\text { Bot } X O \text { : Provides a platform to develop fully } \\
\text { customized conversational AI solutions }\end{array}$ \\
\hline 3 & $\begin{array}{l}\text { Data Analytics } \\
\text { Provider }\end{array}$ & $\begin{array}{l}\text { Provide solutions that integrate and analyze } \\
\text { various data sources for decision support }\end{array}$ & 30 & $\begin{array}{l}\text { Falkonry: Provides a solution that analyzes sensor } \\
\text { and machine data to predict machine operating states }\end{array}$ \\
\hline 4 & $\begin{array}{l}\text { Deep Tech } \\
\text { Researcher }\end{array}$ & $\begin{array}{l}\text { Research and develop basis AI technology for } \\
\text { innovative niche problems }\end{array}$ & 19 & $\begin{array}{l}\text { Cerenion: Researches and develops AI technology } \\
\text { that interprets brain activity }\end{array}$ \\
\hline
\end{tabular}

customers at the core of their business model. Startups of this pattern offer application programmable interfaces or software development kits that can be used for AI development. In addition, some startups offer no-code workbenches, where businesspeople with little IT know-how can develop new AI solutions (e.g., build-your-own chatbot). In this pattern, NLP is often the dominant AI technology. Perhaps, NLP-based solutions, such as chatbots, can barely be standardized and require strong customization to the customer's specific context and individual requirements. Startups of this pattern target business customers across industries and often use subscription-based models for value capture. An example of this pattern is Mindsay, a startup that offers a comprehensive solution for customer service. Their solution is composed of easily configurable chatbots, real-time chat support, and process analytics components. Another example is the startup BotXO. The startup offers a platform to develop fully customized chatbot solutions.

Pattern 3: Data Analytics Provider Startups applying this pattern focus on the integration and analysis of vast amounts of data within their business model, including internal and external data sources. The provided solutions offer comprehensive data analyses to support well-informed decision-making, for example by continuously monitoring operations, uncovering hidden patterns, or making predictions for the future. To that end, the data is typically analyzed using conventional machine learning approaches. For data integration, the solutions often require initial tailoring at the customer. However, the solutions typically connect well with widely used information systems. Startups of this pattern predominately target business customers and employ transaction-based or subscriptionbased revenue models. As an example, the startup Kubit integrates customer information with external data to detect anomalies and predict customer retention and profitability. Another example is Falkonry. The startup offers a solution that integrates sensor and machine data to predict machine operating states. The necessary hardware, such as sensors, is not offered by the startup itself and is therefore not part of the business model.

Pattern 4: Deep Tech Researcher Startups applying this pattern research and develop innovative niche solutions at the frontiers of AI technology as the core of their business model, for example, in the areas of robotics, autonomous driving, and medical drug discovery. Startups of this pattern are often research-led with the aim of driving their AI models and algorithms to perfection. They do not offer standardized or easily customizable solutions for mass markets, but rather deliver the complex base technology that can be implemented and customized by their business customers. Therefore, those startups are not maintaining a stable revenue stream, but, instead, often rely on external funding. In the case of robotics, startups also work on the respective hardware components as part of their business model. As an example, the startup Syrius Robotics develops robots that autonomously transport goods in warehouses and supply production workers with materials. Another example is Cerenion, which develops a software solution to analyze, monitor, and quantify the functioning of the brain based on brain activity.

\section{Discussion}

We currently observe the rapid emergence of startups that use AI technology as part of their products or services. While AI startups receive much interest from venture capitalists and investors, they also need to find a stable business model to ensure long-term performance and survival. In this study, we raised the question of whether the business models of AI startups differ from common ITrelated business models. To investigate this research question, we developed a business model taxonomy of AI startups, which reveals the key characteristics of AI startup business models. We further applied the taxonomy and 
performed a cluster analysis to identify four archetypal business model patterns of AI startups: AI-charged Product/Service Provider, AI Development Facilitator, Data Analytics Provider, and Deep Tech Researcher. Against the background of extant research on IT-related business models, we were able to distill the key distinctive aspects of AI startup business models. Overall, we conclude that AI startup business models share noticeable overlaps with common IT-related business models. For example, they employ similar approaches to value delivery and value capture to those already known from common IT-related business models, such as software-as-a-service or subscription-based revenue models. However, AI startup business models also depart from common IT-related business models in certain aspects. Specifically, we found (1) new value propositions through AI capabilities, (2) different roles of data for value creation, and (3) the impact of AI technology on the overall business logic. In the following, we will elaborate on these distinctive aspects and propose promising directions for entrepreneurship research on AI. Table 4 summarizes potential future research questions. Thereafter, we will discuss the limitations of our research and our contributions to theory and practice.

\subsection{New Value Propositions Through AI Capabilities}

While certain value propositions are well known from research on data-driven business models (e.g., decision support or anomaly detection), we observe that AI technology offers additional capabilities that widen the scope for applying IT to meet new customer needs and ease their pains. In particular, AI startups shift the application of IT toward the domain of knowledge and service work, where human workers are either supported in accomplishing their tasks, or substituted through the automation of robots and bots (Coombs et al. 2020). For example, in certain specific tasks, such as fraud detection or disease diagnosis, AI technology can outperform its human counterparts (Brynjolfsson and McAfee 2017). Given these enhanced capabilities, the question arises how and when AI startups might be able to challenge existing industries, especially those that are knowledge and service work dominant. For example, an AI startup that offers a solution to automate customer support might successfully challenge traditional call center business models due to reduced personnel intensity and enhanced scalability. Prior advances in digitalization have already shown that the use of emergent technologies, such as big data analytics, enables new business models that can disrupt traditional industries (Loebbecke and Picot 2015).

While these AI capabilities open new opportunities, they also imply the need to increasingly consider ethical aspects, both when replacing human workers and when using AI solutions for critical decisions, such as personnel recruitment decisions (Köchling et al. 2021). Interestingly, our analysis did not reveal that these ethical aspects are key characteristics of the business models of AI startups. For example, we would have assumed that AI startups promote the adherence to ethical standards or the algorithmic transparency of their products and services in an effective

Table 4 Future research directions for AI in entrepreneurship

\begin{tabular}{|c|c|c|}
\hline $\begin{array}{l}\text { Distinctive aspect of AI startup } \\
\text { business models }\end{array}$ & Sub-aspect & Potential research question \\
\hline $\begin{array}{l}\text { New value propositions through AI } \\
\text { capabilities }\end{array}$ & $\begin{array}{l}\text { Automation of service and } \\
\text { knowledge work }\end{array}$ & $\begin{array}{l}\text { How and when do AI startups challenge existing service and } \\
\text { knowledge work dominant industries? } \\
\text { What is the potential role of ethics for AI startup business models? }\end{array}$ \\
\hline \multirow[t]{2}{*}{$\begin{array}{l}\text { Different roles of data for value } \\
\text { creation }\end{array}$} & Data access and partnerships & $\begin{array}{l}\text { What are strategies for AI startups to gather training data? } \\
\text { How can digital entrepreneurship ecosystems foster data access? }\end{array}$ \\
\hline & $\begin{array}{l}\text { Different data needs for AI } \\
\text { technology }\end{array}$ & $\begin{array}{l}\text { When is data not essential to the value creation of AI startups? } \\
\text { How does data access influence startup valuation in the context of high } \\
\text { data essentiality? }\end{array}$ \\
\hline \multirow[t]{2}{*}{$\begin{array}{l}\text { Impact of AI technology on the } \\
\text { overall business logic }\end{array}$} & $\begin{array}{l}\text { Mastering complex technology } \\
\text { at the core }\end{array}$ & $\begin{array}{l}\text { How do AI startups gain access to deep technical know-how? } \\
\text { How can AI startups create competitive advantage (e.g., via AI model } \\
\text { leadership)? } \\
\text { What type of AI technology is easier to replicate than others? }\end{array}$ \\
\hline & $\begin{array}{l}\text { Continuous learning and } \\
\text { improvement }\end{array}$ & $\begin{array}{l}\text { How can AI startups challenge competitors that have an AI training } \\
\text { advantage? } \\
\text { What are the implications of continuous learning and data network } \\
\text { effects for entrepreneurship? }\end{array}$ \\
\hline
\end{tabular}


way. Perhaps such an advertising is not required, as most AI startups serve business customers instead of private customers. These business customers are then responsible for communicating ethical aspects to their customers. However, given the importance of ethics for AI solutions (Buxmann et al. 2021), we encourage research to investigate the potential role of ethics in AI startup business models.

\subsection{Different Roles of Data for Value Creation}

While data often plays a vital part in common IT-related business models (e.g., Wiener et al. 2020; Hartmann et al. 2016), we identified different roles of data for value creation in AI startups. For most AI startups, we see that data is an important element of the value creation. This does not come surprisingly, as most of the current upswing of AI is happening thanks to the application of machine learning and the vast availability of data (Haenlein and Kaplan 2019). On the one hand, AI startups analyze or help to analyze data to generate insights or detect anomalies. On the other hand, however, we see the data being used in a different and new way. Especially in the pattern $A I$ charged Product/Service Provider, we observe that data is not analyzed to create insights; instead, data is used to train models that are then readily embedded in products and services. For example, a computer vision algorithm is trained to detect certain diseases, which then can be transferred and applied across hospitals. Here, the value is delivered by a readily trained model instead of providing the means for new data analysis.

Given the important role of data for most AI startups, data acquisition becomes an important part of the business model, as evident in our taxonomy (data source and data type). Similar to previous findings, we can state that AI startups can leverage data in various types and from various sources as part of their value creation, such as selfgenerated data, external customer data, or publicly available data (Bock and Wiener 2017; Hartmann et al. 2016). To gain access to more exclusive data, we see some AI startups form close relationships with industry partners, for example to obtain real-world data from manufacturing. For entrepreneurship, the question arises how AI startups potentially follow different strategies to access or gather data. And, in turn, how digital entrepreneurship ecosystems (Elia et al. 2020) might foster data to facilitate entrepreneurial action. These questions should be examined against the background of extant research on data-driven business models (e.g., Wiener et al. 2020).

Despite the importance of data to some AI startups and the common assumption that $\mathrm{AI}$ is data intensive, we argue that not all AI startup business models are equally dependent on data. For example, certain machine learning techniques used as primary AI technology require substantially less data (Benbya et al. 2020), or some AI startups are leveraging publicly available data for value creation. Future research needs to further explore the essentiality of data for AI startups and its implications in various contexts. When and in what contexts do AI startups not heavily rely on data? Given a high data essentiality in a specific context, what does the possession of rare or scarce data imply for the valuation of a startup? For this, it will be indispensable to take a more nuanced perspective on AI in entrepreneurship to account for the different AI techniques (Stone et al. 2016) and application contexts.

\subsection{Impact of AI Technology on the Overall Business Logic}

Our taxonomy and patterns reveal that AI startup business models are strongly technology-centered, which led us to examine how AI, a different technology compared to traditional IT, impacts the overall business logic. We identified many technical dimensions and characteristics in our taxonomy (e.g., continuous learning, primary AI technology, data source) that seemingly overshadow other aspects, such as the target customer or revenue model. AI startups are mostly focused on giving their business customers access to complex AI technology that is otherwise too difficult and costly for these to develop (Jöhnk et al. 2021). Our patterns revealed different archetypes on how this technical complexity is mastered and delivered: by means of providing products and services with pre-trained AI models (AI-charged Product/Service Provider), facilitating development with customizable and programmable interfaces (AI Development Facilitator), providing solutions for data analytics (Data Analytics Provider), and researching and developing basis AI technology (Deep Tech Researcher).

This focus on mastering the technical complexity raises interesting questions for future research into entrepreneurship. One aspect certainly is how AI startups manage to obtain access to in-depth technical know-how and extensive resources, as other scholars have mentioned 
previously (Chalmers et al. 2020; Obschonka and Audretsch 2020). Another aspect is how AI startups can make themselves stand out against competitors. One possible way could be to obtain leadership in the underlying algorithms and their performance. For example, the startup DeepL managed to build a natural language translation software that outperformed tech giants like Google, Facebook and Amazon (Coldewey and Lardinois 2017). We would expect that especially startups of the type $A I$ charged Product/Service Provider and Deep Tech Researcher are likely to follow this direction, as their offering mostly depends on the performance of the AI models. Other potential ways could be the provision of a well usable and comprehensive solution that goes beyond single AI-based features (e.g., covering the whole marketing process), or the provision of a very flexible and customizable solution (e.g., build-your-own chatbot). This discussion opens fruitful avenues for future research: How can AI startups create competitive advantage (e.g., via AI model leadership)? What type of AI technology is easier to replicate than others?

Furthermore, our taxonomy reveals that the continuous learning of AI-based products and services is an interesting mechanism that impacts the overall business logic. The products and services can potentially become smarter over time while in use by the customer, or through federated learning and central updates from the provider, as more data becomes available for AI training. Given this mechanism, an early mover could build a critical customer base first and obtain a competitive advantage through the data that is collected from the customers, because this data then would allow to refine the algorithms and increase the value of the service, which in turn would attract more customers (Gregory et al. 2020). Would another startup be able to catch up with a bigger dataset and better algorithms, or maybe compensate this technical disadvantage with better usability or branding? More research is needed to understand the implications of continuous learning and data network effects in the context of entrepreneurship.

\subsection{Limitations and Extensions}

Our research comes with limitations. First, taxonomies, in general, can never be fully exhaustive or perfect (Nickerson et al. 2013). However, we were able to ensure the appropriateness and usefulness of the taxonomy by following the structured and proven method proposed by
Nickerson et al. (2013). Nevertheless, we do recognize that our taxonomy likely needs to be reviewed and extended in upcoming years since the field of AI is evolving fast (Stone et al. 2016). Second, we used Crunchbase for startup identification, which relies on self-reported information. Consequently, we could not identify all startups that use AI technology as an important element of their business model, as some might refrain from reporting the use of AI technology explicitly. Nevertheless, we are confident that our sample featured enough startups to capture the diversity of the underlying business models. Third, our taxonomy and patterns were mainly built with AI startups from North America and Europe, as Crunchbase tends to predominately feature Western countries. Therefore, our results should be treated with caution when applying them to AI startups from other countries. Accounting for national differences, such as data-related regulations (Wiener et al. 2020), is beyond the scope of our study.

\subsection{Contributions to Theory and Implications for Practice}

Our work contributes to a growing research stream of AI in entrepreneurship (Chalmers et al. 2020; Obschonka and Audretsch 2020) and to research on IT-related business models (Veit et al. 2014; Steininger 2019). First, we addressed the research question of how AI startups business models potentially differ from common IT-related business models. Using our descriptive analysis as a vantage point (Gregor 2006), we were able to distill the distinctive aspects of AI startup business models. We can conclude that while AI startup business models indeed share noticeable overlaps in some aspects, they certainly go beyond common IT-related business models, such as datadriven business models. Second, we further elaborated on these differences and their implications, which enabled us to present promising directions for future research on $\mathrm{AI}$ in entrepreneurship. Here, we particularly argue for a more nuanced perspective on AI in entrepreneurship, because our analysis showed that AI startups apply different AI techniques which each have different implications for the business model. Third, we provided one of the first comprehensive analyses of AI startup business models. We revealed the key dimensions and characteristics of $\mathrm{AI}$ startup business models and derived respective patterns. Previous business model research has predominately assessed the implications of AI technology to enhance 
operations as part of the value creation, whereas the overall business model remained mostly unstudied (Garbuio and Lin 2019). Our taxonomy and patterns can serve as a springboard for future research, because they represent clearly defined categories that allow for an in-depth examination (Rich 1992). For example, one could use the patterns to develop a typology (Doty and Glick 1994) of AI startups, which links the patterns to specific outcomes (e.g., venture growth).

Our work has relevant implications for practice. First, our business model taxonomy for AI startups supports entrepreneurs in developing and innovating business models by using AI technology. It serves as a morphological box, meaning that every combination of dimensions results in a new business model. In addition, the four archetypal patterns reveal interesting insights into common instantiations of AI startup business models. They could be considered as current best-practice and may serve as a blueprint for new ventures. Second, our work is also relevant for managers of larger and more established firms. As Hartmann et al. (2016, p.2) note, in comparison with larger firms, "young companies create a rich variety of, presumably, purer business models." Hence, our investigation might have also revealed opportunities for larger firms, because some elements of AI startup business models could be directly applicable. Third, we support venture capitalists and investors in making more profound decisions regarding AI startups. We help to structure a vast landscape of AI startups and provide the key characteristics of business models to be considered for AI startup evaluation. Given the prevalence of technical dimensions in the business model, we recommend venture capitalists and investors to develop a good technical understanding of AI technology to appropriately evaluate the potential of an AI startup.

\section{Conclusion}

We currently observe the rapid emergence of startups that use AI technology as part of their products or services. While AI startups receive much interest from venture capitalists and investors, they inevitably need to find a stable business model at one point to ensure long-term performance and survival. On the one hand, recent research led us to suggest that AI startups do employ novel or dif- ferent business models. On the other hand, we also found compelling arguments that much of what is sold as AI today has been around for a long time already. Because a fundamental clarification would be important for both research and practice, we raised the question of how AI startup business models potentially differ from common IT-related business models. To investigate this research question, we developed a business model taxonomy of AI startups, which revealed the key characteristics of AI startup business models. We further applied the taxonomy and performed a cluster analysis to derive four archetypal business model patterns of AI startups: AI-charged Product/Service Provider, AI Development Facilitator, Data Analytics Provider, and Deep Tech Researcher. Against the background of extant research on IT-related business models, we further distilled the distinctive aspects of AI startup business models. We found that (1) AI capabilities open new opportunities for value proposition, (2) data features different roles and is typically-yet not necessarily-important to the value creation, and (3) AI technology impacts the overall business logic in potentially new ways. We further discussed promising directions for future research on AI in entrepreneurship.

We contribute to a growing research stream concerned with AI in entrepreneurship (Chalmers et al. 2020; Obschonka and Audretsch 2020) and to research on ITrelated business models (Veit et al. 2014; Steininger 2019). First, we distilled the distinctive aspects of AI startup business models to sharpen our understanding of the impact of AI technology on entrepreneurship and business models. Second, we presented promising directions to guide future research on AI in entrepreneurship. Third, we provided one of the first comprehensive analysis of AI-related business models. Our taxonomy and patterns reveal the key dimensions and characteristics of AI startup business models and their common instantiations. Practitioners may use our taxonomy and patterns as tools to support entrepreneurial action. Furthermore, we help to structure a broad and diverse AI startup landscape.

\section{Appendix}

See Tables 5, 6 . 
Table 5 List of AI startups used for taxonomy and pattern development

\begin{tabular}{|c|c|c|c|c|c|c|}
\hline \# & Organization Name & Website (last accessed 1 March 2021) & Country & $\begin{array}{l}\text { Founding } \\
\text { year }\end{array}$ & $\begin{array}{l}\text { Funding } \\
(\$ \mathrm{M})\end{array}$ & $\begin{array}{l}\text { Cluster/ } \\
\text { Pattern }\end{array}$ \\
\hline 1 & Notable & http://notablehealth.com/ & United States & 2017 & 19.20 & 1 \\
\hline 2 & Gamaya & https://gamaya.com & Switzerland & 2014 & 20.23 & 1 \\
\hline 3 & Saykara & http://saykara.com/ & United States & 2015 & 7.50 & 1 \\
\hline 4 & Aiconix.ai & http://www.aiconix.ai/ & Germany & 2018 & 1.25 & 1 \\
\hline 5 & GroupSolver Inc & https://groupsolver.com & United States & 2014 & 3.00 & 1 \\
\hline 6 & NEXT Future Transportation & http://next-future-transportation.com & United States & 2015 & 1.24 & 4 \\
\hline 7 & TabSquare & https://www.tabsquare.ai & Singapore & 2012 & 13.23 & 3 \\
\hline 8 & Daloopa & https://www.daloopa.com & United States & 2019 & 3.40 & 2 \\
\hline 9 & Resonance AI & http://www.resonanceai.com & United States & 2013 & 5.76 & 1 \\
\hline 10 & Zebrium & https://www.zebrium.com/ & United States & 2018 & 6.31 & 3 \\
\hline 11 & Banuba & https://banuba.com/ & Belarus & 2016 & 12.00 & 2 \\
\hline 12 & Miuros & http://www.miuros.com & France & 2016 & 2.39 & 3 \\
\hline 13 & Syte & https://www.syte.ai/ & Israel & 2015 & 71.60 & 3 \\
\hline 14 & Cerenion & http://cerenion.com & Finland & 2017 & 2.83 & 4 \\
\hline 15 & Sonantic & https://sonantic.io/ & $\begin{array}{l}\text { United } \\
\text { Kingdom }\end{array}$ & 2018 & 2.57 & 2 \\
\hline 16 & Worthix & https://www.worthix.com/ & United States & 2015 & 24.10 & 1 \\
\hline 17 & Aquant & http://www.aquant.io & United States & 2016 & 42.60 & 3 \\
\hline 18 & OnePointOne & http://onepointone.com & United States & 2017 & 24.00 & 4 \\
\hline 19 & Albert Technologies & https://www.albert.ai & United States & 2010 & 18.00 & 3 \\
\hline 20 & Lucena Research & http://lucenaresearch.com & United States & 2014 & 2.93 & 3 \\
\hline 21 & KONUX & http://konux.com & Germany & 2014 & 51.63 & 4 \\
\hline 22 & Viz & http://www.viz.ai/ & United States & 2016 & 80.55 & 1 \\
\hline 23 & ISEE & http://isee.ai & United States & 2017 & 17.74 & 4 \\
\hline 24 & Hugging Face & https://huggingface.co/ & United States & 2016 & 20.20 & 2 \\
\hline 25 & Wysdom.AI & https://wysdom.ai/ & Canada & 2012 & 12.00 & 2 \\
\hline 26 & Recursion Pharmaceuticals & http://www.recursionpharma.com & United States & 2013 & 465.38 & 4 \\
\hline 27 & $R A D i C A L$ & http://www.getrad.co & United States & 2017 & 1.60 & 1 \\
\hline 28 & Falkonry & http://falkonry.com/ & United States & 2013 & 11.30 & 3 \\
\hline 29 & Subtle Medical & https://subtlemedical.com/ & United States & 2017 & 1.10 & 1 \\
\hline 30 & Alegion & http://www.alegion.com/ & United States & 2012 & 16.10 & 1 \\
\hline 31 & Cresta & https://www.cresta.com/ & United States & 2017 & 21.00 & 2 \\
\hline 32 & Onfido & http://www.onfido.com & $\begin{array}{l}\text { United } \\
\text { Kingdom }\end{array}$ & 2012 & 188.76 & 1 \\
\hline 33 & Tend.ai & https://tend.ai/ & United States & 2016 & 2.00 & 3 \\
\hline 34 & Blue Hexagon & http://bluehexagon.ai/ & United States & 2017 & 37.00 & 3 \\
\hline 35 & Shield AI & http://www.shield.ai & United States & 2015 & 48.14 & 4 \\
\hline 36 & Integrate.ai & https://integrate.ai/ & Canada & 2017 & 39.58 & 3 \\
\hline 37 & BotXO & http://www.botxo.co & Denmark & 2016 & 5.06 & 2 \\
\hline 38 & Osaro & http://www.osaro.com/ & United States & 2015 & 29.30 & 4 \\
\hline 39 & SmartBeings & http://www.smartbeings.com & United States & 2015 & 2.03 & 2 \\
\hline 40 & Windward & http://www.wnwd.com/ & Israel & 2010 & 32.30 & 3 \\
\hline 41 & Cyclica & http://www.cyclicarx.com & Canada & 2013 & 23.81 & 4 \\
\hline 42 & $\begin{array}{l}\text { Synapse Technology } \\
\text { Corporation }\end{array}$ & https://www.synapsetechnology.com/ & United States & 2016 & 8.50 & 1 \\
\hline 43 & Mindsay & https://www.mindsay.com & France & 2016 & 11.23 & 2 \\
\hline 44 & Largo & http://largo.ai/ & Switzerland & 2018 & 1.70 & 1 \\
\hline 45 & Overjet & https://www.overjet.ai/ & United States & 2018 & 7.85 & 1 \\
\hline
\end{tabular}


Table 5 continued

\begin{tabular}{|c|c|c|c|c|c|c|}
\hline \# & Organization Name & Website (last accessed 1 March 2021) & Country & $\begin{array}{l}\text { Founding } \\
\text { year }\end{array}$ & $\begin{array}{l}\text { Funding } \\
(\$ \mathrm{M})\end{array}$ & $\begin{array}{l}\text { Cluster/ } \\
\text { Pattern }\end{array}$ \\
\hline 46 & RubiQ & http://www.rubiq.tech & Israel & 2018 & 1.10 & 3 \\
\hline 47 & LinkSquares & https://www.linksquares.com/ & United States & 2015 & 21.47 & 2 \\
\hline 48 & ParallelDots & http://www.paralleldots.com/ & India & 2017 & 1.40 & 1 \\
\hline 49 & Elucidata Corporation & http://www.elucidata.io/ & India & 2015 & 1.70 & 4 \\
\hline 50 & Humanising Autonomy & $\begin{array}{l}\text { https://www.humanisingautonomy. } \\
\text { com }\end{array}$ & $\begin{array}{l}\text { United } \\
\text { Kingdom }\end{array}$ & 2017 & 6.00 & 4 \\
\hline 51 & Deeplite & http://www.deeplite.ai & Canada & 2018 & 1.92 & 2 \\
\hline 52 & Loris & https://www.loris.ai/ & United States & 2018 & 7.14 & 2 \\
\hline 53 & Infervision & http://www.infervision.com/ & China & 2015 & 74.66 & 1 \\
\hline 54 & Contexta360 & https://contexta360.com/ & The Netherlands & 2016 & 1.12 & 2 \\
\hline 55 & Whizar Artificial Intelligence & http://www.whizar.com/ & Israel & 2017 & 5.70 & 3 \\
\hline 56 & PolyAI & http://www.poly-ai.com/ & $\begin{array}{l}\text { United } \\
\text { Kingdom }\end{array}$ & 2017 & 12.00 & 2 \\
\hline 57 & Senso.ai & http://www.senso.ai & Canada & 2016 & 4.90 & 3 \\
\hline 58 & TорOPPS & http://www.topopps.com & United States & 2014 & 8.30 & 3 \\
\hline 59 & teleport $H Q$ & https://teleporthq.io/ & Romania & 2017 & 1.17 & 1 \\
\hline 60 & Compology & http://www.compology.com & United States & 2013 & 38.04 & 4 \\
\hline 61 & Rubikloud & http://www.rubikloud.ai & Canada & 2013 & 45.50 & 3 \\
\hline 62 & SuperAnnotate & https://www.superannotate.ai/ & United States & 2018 & 3.00 & 1 \\
\hline 63 & Elemental Machines & http://elementalmachines.io/ & United States & 2015 & 16.68 & 4 \\
\hline 64 & Apollo Agriculture & https://www.apolloagriculture.com & Kenya & 2016 & 7.59 & 1 \\
\hline 65 & ArtiQ & https://www.artiq.eu/ & Belgium & 2019 & 1.13 & 4 \\
\hline 66 & OTO Systems & https://www.oto.ai/ & United States & 2017 & 5.30 & 2 \\
\hline 67 & Serenus.AI & http://www.serenusai.com & Israel & 2016 & 2.70 & 4 \\
\hline 68 & TheTake & http://www.thetake.ai & United States & 2013 & 2.00 & 3 \\
\hline 69 & Fama & http://www.fama.io/ & United States & 2015 & 7.70 & 3 \\
\hline 70 & Axonize & http://www.axonize.com/ & Israel & 2016 & 7.80 & 3 \\
\hline 71 & Loom Systems & http://www.loomsystems.com & United States & 2015 & 16.00 & 3 \\
\hline 72 & Iterative Scopes & http://www.iterativescopes.com & United States & 2017 & 5.20 & 1 \\
\hline 73 & FunnelAI & https://www.funnelai.com & United States & 2017 & 2.11 & 2 \\
\hline 74 & LeanTaaS & https://leantaas.com/ & United States & 2010 & 107.75 & 3 \\
\hline 75 & Tonal & http://www.tonal.com & United States & 2015 & 200.00 & 4 \\
\hline 76 & DataProphet & http://dataprophet.com & South Africa & 2014 & 6.00 & 3 \\
\hline 77 & ProFinda & http://www.profinda.com & $\begin{array}{l}\text { United } \\
\text { Kingdom }\end{array}$ & 2011 & 7.71 & 3 \\
\hline 78 & $F L Y R$ & http://flyrlabs.com & United States & 2013 & 25.34 & 3 \\
\hline 79 & Viv & http://viv.ai/ & United States & 2012 & 30.00 & 2 \\
\hline 80 & Leena AI & https://www.leena.ai/ & United States & 2015 & 2.00 & 2 \\
\hline 81 & Granify & http://granify.com & Canada & 2011 & 13.48 & 3 \\
\hline 82 & Vestorly & http://www.vestorly.com/ & United States & 2012 & 14.60 & 2 \\
\hline 83 & Formalytics & http://formalytics.io/ & Australia & 2016 & 1.65 & 1 \\
\hline 84 & Envisagenics & http://envisagenics.com/ & United States & 2014 & 5.58 & 4 \\
\hline 85 & Diffbot & http://www.diffbot.com & United States & 2010 & 13.00 & 2 \\
\hline 86 & Looka & https://logojoy.com & Canada & 2016 & 5.46 & 1 \\
\hline 87 & Logz.io & https://logz.io/ & Israel & 2014 & 98.90 & 3 \\
\hline 88 & Cameralyze & https://www.cameralyze.com & Turkey & 2019 & 10.00 & 1 \\
\hline 89 & DISCO & http://www.csdisco.com/ & United States & 2012 & 193.58 & 2 \\
\hline 90 & Aiola & http://aiola.com & Israel & 2019 & 3.00 & 2 \\
\hline
\end{tabular}


Table 5 continued

\begin{tabular}{|c|c|c|c|c|c|c|}
\hline \# & Organization Name & Website (last accessed 1 March 2021) & Country & $\begin{array}{l}\text { Founding } \\
\text { year }\end{array}$ & $\begin{array}{l}\text { Funding } \\
(\$ M)\end{array}$ & $\begin{array}{l}\text { Cluster/ } \\
\text { Pattern }\end{array}$ \\
\hline 91 & Kubit & https://www.kubit.ai & United States & 2018 & 4.50 & 3 \\
\hline 92 & VoiceBase & http://www.voicebase.com & United States & 2010 & 31.50 & 2 \\
\hline 93 & Sensifai & http://www.sensifai.com & Belgium & 2016 & 1.52 & 1 \\
\hline 94 & Fakespot & http://fakespot.com & United States & 2016 & 1.30 & 3 \\
\hline 95 & TerraClear & https://www.terraclear.com/ & United States & 2017 & 13.12 & 4 \\
\hline 96 & Raw Shorts & http://rawshorts.com & United States & 2013 & 2.27 & 1 \\
\hline 97 & Wootric & http://www.wootric.com & United States & 2013 & 2.60 & 3 \\
\hline 98 & Light Information Systems & http://www.nlpbots.com & India & 2012 & 2.26 & 2 \\
\hline 99 & Syrius Robotics & http://www.syriusrobotics.com/ & China & 2018 & 11.15 & 4 \\
\hline 100 & AllyO & https://www.allyo.com/ & United States & 2015 & 64.00 & 2 \\
\hline
\end{tabular}

Table 6 Salient characteristics of business model patterns

\begin{tabular}{|c|c|c|c|c|}
\hline \multirow[t]{2}{*}{ Dimension } & \multicolumn{4}{|c|}{ Salient characteristics (SMD score in brackets) } \\
\hline & $\begin{array}{l}\text { AI-charged Product/Service } \\
\text { Provider }\end{array}$ & AI Development Facilitator & Data Analytics Provider & Deep Tech Researcher \\
\hline Core AI value & $\begin{array}{l}\text { Process and task support } \\
(1.460)\end{array}$ & $\begin{array}{l}\text { Process and task support } \\
(1.003)\end{array}$ & $\begin{array}{l}\text { Monitoring and anomaly } \\
\text { detection } \\
(0.935)\end{array}$ & $\begin{array}{l}\text { Autonomous robots \& } \\
\text { bots } \\
(0.927)\end{array}$ \\
\hline $\begin{array}{l}\text { Continuous } \\
\text { learning }\end{array}$ & $\begin{array}{l}\text { Learning at customer side } \\
(0.972)\end{array}$ & $\begin{array}{l}\text { Central learning and updates } \\
(0.658)\end{array}$ & $\begin{array}{l}\text { Not provided } \\
(1.060)\end{array}$ & $\begin{array}{l}\text { Not provided } \\
(0.594)\end{array}$ \\
\hline $\begin{array}{l}\text { Primary AI } \\
\text { technology }\end{array}$ & $\begin{array}{l}\text { Computer vision } \\
(1.458)\end{array}$ & $\begin{array}{l}\text { Natural language processing } \\
(1.458)\end{array}$ & $\begin{array}{l}\text { Machine learning } \\
(1.481)\end{array}$ & $\begin{array}{l}\text { Robotics } \\
(1.190)\end{array}$ \\
\hline Data type & $\begin{array}{l}\text { Visual data } \\
(1.573)\end{array}$ & $\begin{array}{l}\text { Textual/document data \& Natural } \\
\text { language data } \\
\text { (1.091 each) }\end{array}$ & $\begin{array}{l}\text { Numeric/sensor data } \\
(1.571)\end{array}$ & $\begin{array}{l}\text { Numeric/sensor data } \\
(1.105)\end{array}$ \\
\hline Data source & $\begin{array}{l}\text { Customer provided on } \\
\text { demand } \\
(1.618)\end{array}$ & $\begin{array}{l}\text { Customer provided on demand } \\
(0.981)\end{array}$ & $\begin{array}{l}\text { Customer transmitted } \\
\text { continuously } \\
(1.625)\end{array}$ & $\begin{array}{l}\text { Self-generated } \\
(1.608)\end{array}$ \\
\hline $\begin{array}{l}\text { Hardware } \\
\text { provision }\end{array}$ & $\begin{array}{l}\text { No } \\
(0.707)\end{array}$ & $\begin{array}{l}\text { No } \\
(0.707)\end{array}$ & $\begin{array}{l}\text { No } \\
(0.707)\end{array}$ & $\begin{array}{l}\text { Yes } \\
(0.707)\end{array}$ \\
\hline Delivery mode & $\begin{array}{l}\text { Software application } \\
(1.448)\end{array}$ & $\begin{array}{l}\text { Programmable interface } \\
(1.225)\end{array}$ & $\begin{array}{l}\text { Software application } \\
(1.477)\end{array}$ & $\begin{array}{l}\text { Base technology } \\
(1.124)\end{array}$ \\
\hline $\begin{array}{l}\text { Level of } \\
\text { customization }\end{array}$ & $\begin{array}{l}\text { Standardized product/ } \\
\text { service } \\
(1.094)\end{array}$ & $\begin{array}{l}\text { Tailoring/individualization } \\
(0.718)\end{array}$ & $\begin{array}{l}\text { Tailoring/individualization } \\
\text { (1.122) }\end{array}$ & $\begin{array}{l}\text { Standardized product/ } \\
\text { service } \\
(0.593)\end{array}$ \\
\hline Customer & $\begin{array}{l}\text { Both } \\
(0.812)\end{array}$ & $\begin{array}{l}\text { B2B and B2C } \\
(0.577 \text { each })\end{array}$ & $\begin{array}{l}\text { B2B } \\
(1.067)\end{array}$ & $\begin{array}{l}\text { Both } \\
(1.154)\end{array}$ \\
\hline Industry scope & $\begin{array}{l}\text { Industry focused } \\
(0.707)\end{array}$ & $\begin{array}{l}\text { Industry agnostic } \\
(0.707)\end{array}$ & $\begin{array}{l}\text { Industry agnostic } \\
(0.707)\end{array}$ & $\begin{array}{l}\text { Industry focused } \\
(0.707)\end{array}$ \\
\hline Customer charge & $\begin{array}{l}\text { Transaction-based } \\
(0.944)\end{array}$ & $\begin{array}{l}\text { Subscription-based } \\
(1.420)\end{array}$ & $\begin{array}{l}\text { Transaction-based } \\
(1.389)\end{array}$ & $\begin{array}{l}\text { Subscription-based } \\
(0.888)\end{array}$ \\
\hline
\end{tabular}

To determine the salient characteristics, we calculated the standardized mean differences (SMD) of the characteristics' relative occurrences compared to their relative occurrences across the sample. For a given dimension and pattern, the selected salient characteristic has the highest SMD 
Supplementary InformationThe online version contains supplementary material available at https://doi.org/10.1007/s12599021-00732-w.

Acknowledgements We sincerely thank the editors and three anonymous reviewers whose constructive comments helped to guide the development of this paper throughout the review process.

Funding Open Access funding enabled and organized by Projekt DEAL

Open Access This article is licensed under a Creative Commons Attribution 4.0 International License, which permits use, sharing, adaptation, distribution and reproduction in any medium or format, as long as you give appropriate credit to the original author(s) and the source, provide a link to the Creative Commons licence, and indicate if changes were made. The images or other third party material in this article are included in the article's Creative Commons licence, unless indicated otherwise in a credit line to the material. If material is not included in the article's Creative Commons licence and your intended use is not permitted by statutory regulation or exceeds the permitted use, you will need to obtain permission directly from the copyright holder. To view a copy of this licence, visit http://creativecommons. org/licenses/by/4.0/.

\section{References}

Ågerfalk PJ (2020) Artificial intelligence as digital agency. Eur J Inf Syst 29(1):1-8

Amshoff B, Dülme C, Echterfeld J, Gausemeier J (2015) Business model patterns for disruptive technologies. Int $\mathrm{J}$ Innov Manag 19(03): 1540002

Armour J, Sako M (2020) AI-enabled business models in legal services: from traditional law firms to next-generation law companies? J Prof Organ 7(1):27-46

Benbya H, Davenport TH, Pachidi S (2020) Artificial intelligence in organizations: current state and future opportunities. MIS Q Exec 19(4):ix-xxi

Berente N, Gu B, Recker J, Santhanam R (2021) Managing artificial intelligence. MIS Q 45(3):1433-1450

Bock M, Wiener M (2017) Towards a taxonomy of digital business models-conceptual dimensions and empirical illustrations. In: Proceedings of the 38th International Conference on Information Systems, Seoul

Böhm M, Weking J, Fortunat F, Müller S, Welpe I, Krcmar H (2017) The business model DNA: towards an approach for predicting business model success. In: Proceedings der 13. Internationalen Tagung Wirtschaftsinformatik, St. Gallen

Borges AFS, Laurindo FJB, Spínola MM, Gonçalves RF, Mattos CA (2021) The strategic use of artificial intelligence in the digital era: systematic literature review and future research directions. Int J Inf Manag 57:102225

Brooks C, Gherhes C, Vorley T (2020) Artificial intelligence in the legal sector: pressures and challenges of transformation. Camb J Reg Econ Soc 13(1):135-152

Brynjolfsson E, McAfee A (2017) The business of artificial intelligence. Harv Bus Rev. https://hbr.org/2017/07/the-business-ofartificial-intelligence. Accessed 12 January 2021

Buxmann P, Hess T, Thatcher JB (2021) AI-based information systems. Bus Inf Syst Eng 63(1):1-4

Canhoto AI, Clear F (2020) Artificial intelligence and machine learning as business tools: a framework for diagnosing value destruction potential. Bus Horizons 63(2):183-193
Chalmers D, MacKenzie NG, Carter S (2020) Artificial intelligence and entrepreneurship: implications for venture creation in the fourth industrial revolution. Entrepreneurship Theor Pract 45(5):1028-1053

Chesbrough H (2010) Business model innovation: opportunities and barriers. Long Range Plan 43(2-3):354-363

Chong AYL, Lim ET, Hua X, Zheng S, Tan C-W (2019) Business on chain: a comparative case study of five blockchain-inspired business models. J Assoc Inf Syst 20(9):1310-1339

Coldewey D, Lardinois F (2017) DeepL schools other online translators with clever machine learning. TechCrunch. https:// techcrunch.com/2017/08/29/deepl-schools-other-online-transla tors-with-clever-machine-learning/. Accessed 28 June 2021

Coombs C, Hislop D, Taneva SK, Barnard S (2020) The strategic impacts of Intelligent automation for knowledge and service work: an interdisciplinary review. J Strateg Inf Syst 29(4): 101600

Davenport T, Ronanki R (2018) Artificial intelligence for the real world. Harv Bus Rev 96(1):108-116

Davenport T, Guha A, Grewal D, Bressgott T (2020) How artificial intelligence will change the future of marketing. J Acad Mark Sci 48(1):24-42

Davidsson P, Recker J, von Briel F (2020) External enablement of new venture creation: a framework. Acad Manag Perspect 34(3):311-332

Doty DH, Glick WH (1994) Typologies as a unique form of theory building: toward improved understanding and modeling. Acad Manag Rev 19(2):230-251

Ehret M, Wirtz J (2017) Unlocking value from machines: business models and the industrial internet of things. J Mark Manag 33(1-2):111-130

Elia G, Margherita A, Passiante G (2020) Digital entrepreneurship ecosystem: How digital technologies and collective intelligence are reshaping the entrepreneurial process. Technol Forecasting Soc Change 150:119791

Floetgen RJ, Strauss J, Weking J, Hein A, Urmetzer F, Böhm M, Krcmar H (2021) Introducing platform ecosystem resilience: leveraging mobility platforms and their ecosystems for the new normal during COVID-19. Eur J Inf Syst 30(3):304-321

Garbuio M, Lin N (2019) Artificial intelligence as a growth engine for health care startups: emerging business models. Calif Manag Rev 61(2):59-83

Gassmann O, Frankenberger K, Csik M (2014) The business model navigator: 55 models that will revolutionise your business. Pearson, Harlow

George G, Bock AJ (2011) The business model in practice and its implications for entrepreneurship research. Entrepreneurship Theor Pract 35(1):83-111

Gregor S (2006) The nature of theory in information systems. MIS Q 30(3):611-642

Gregory RW, Henfridsson O, Kaganer E, Kyriakou H (2020) The role of artificial intelligence and data network effects for creating user value. Acad Manag Rev 46(3):534-551

Haenlein M, Kaplan A (2019) A brief history of artificial intelligence: on the past, present, and future of artificial intelligence. Calif Manag Rev 61(4):5-14

Hartmann PM, Zaki M, Feldmann N, Neely A (2016) Capturing value from big data - a taxonomy of data-driven business models used by start-up firms. Int J Oper Prod Manag 36(10):1382-1406

Hein A, Schreieck M, Riasanow T, Soto Setzke D, Wiesche M, Böhm M, Krcmar H (2020) Digital platform ecosystems. Electron Mark 30(1):87-98

Jöhnk J, Weißert M, Wyrtki K (2021) Ready or not, AI comes-an interview study of organizational AI readiness factors. Bus Inf Syst Eng 63(1):5-20 
Jordan MI, Mitchell TM (2015) Machine learning: trends, perspectives, and prospects. Sci 349(6245):255-260

Ketchen DJ, Shook CL (1996) The application of cluster analysis in strategic management research: an analysis and critique. Strateg Manag J 17(6):441-458

Köchling A, Riazy S, Wehner MC, Simbeck K (2021) Highly accurate, but still discriminatory. Bus Inf Syst Eng 63(1):39-54

LeCun Y, Bengio Y, Hinton G (2015) Deep learning. Nature 521(7553):436-444

Loebbecke C, Picot A (2015) Reflections on societal and business model transformation arising from digitization and big data analytics: a research agenda. J Strateg Inf Syst 24(3):149-157

Makridakis S (2017) The forthcoming Artificial intelligence (AI) revolution: its impact on society and firms. Futures 90:46-60

Massa L, Tucci CL, Afuah A (2017) A critical assessment of business model research. Acad Manag Ann 11(1):73-104

Nickerson RC, Varshney U, Muntermann J (2013) A method for taxonomy development and its application in information systems. Eur J Inf Syst 22(3):336-359

Obschonka M, Audretsch DB (2020) Artificial intelligence and big data in entrepreneurship: a new era has begun. Small Bus Econ 55(3):529-539

OECD (2018) Private equity investment in artificial intelligence. OECD Going Digital Policy Note. OECD, Paris

Osterwalder A, Pigneur Y (2010) Business model generation: a handbook for visionaries, game changers, and challengers. Wiley, Hoboken

Rai A, Constantinides P, Sarker S (2019) Editor's comments: nextgeneration digital platforms: toward human-AI hybrids. MIS Q 43(1): iii-X

Remane G, Hanelt A, Tesch JF, Kolbe LM (2017) The business model pattern database - a tool for systematic business model innovation. Int J Innov Manag 21(1):1750004

Rich P (1992) The organizational taxonomy: definition and design. Acad Manag Rev 17(4):758-781

Russell S, Norvig P (2016) Artificial intelligence: a modern approach. Pearson, Boston

Sarstedt M, Mooi E (2014) A concise guide to market research-the process, data, and methods using IBM SPSS statistics, vol 12. Springer, Heidelberg

Spiegel O, Abbassi P, Zylka MP, Schlagwein D, Fischbach K, Schoder D (2016) Business model development, founders' social capital and the success of early stage internet start-ups: a mixedmethod study. Inf Syst J 26(5):421-449
Steininger DM (2019) Linking information systems and entrepreneurship: a review and agenda for IT-associated and digital entrepreneurship research. Inf Syst J 29(2):363-407

Stone P, Brooks R, Brynjolfsson E, Calo R, Etzioni O, Hager G, Hirschberg J, Kalyanakrishnan S, Kamar E, Kraus S, LeytonBrown K, Parkes D, Press W, Saxenian A, Shah J, Tambe M, Teller A (2016) Artificial intelligence and life in 2030. One hundred year study on artificial intelligence. Stanford University, Stanford

Täuscher K, Laudien SM (2018) Understanding platform business models: a mixed methods study of marketplaces. Eur Manag J 36(3):319-329

Teece DJ (2010) Business models, business strategy and innovation. Long Range Plan 43(2-3):172-194

Valter P, Lindgren P, Prasad R (2018) Advanced business model innovation supported by artificial intelligence and deep learning. Wirel Pers Commun 100(1):97-111

Veit D, Clemons E, Benlian A, Buxmann P, Hess T, Kundisch D, Leimeister JM, Loos P, Spann M (2014) Business models. Bus Inf Syst Eng 6(1):45-53

Weking J, Hein A, Böhm M, Krcmar H (2020a) A hierarchical taxonomy of business model patterns. Electron Mark 30(3):447-468

Weking J, Mandalenakis M, Hein A, Hermes S, Böhm M, Krcmar H (2020b) The impact of blockchain technology on business models - a taxonomy and archetypal patterns. Electron Mark 30(2):285-305

Weking J, Stöcker M, Kowalkiewicz M, Böhm M, Krcmar H (2020c) Leveraging industry $4.0-$ a business model pattern framework. Int J Prod Econ 225:107588

Wiener M, Saunders C, Marabelli M (2020) Big-data business models: a critical literature review and multiperspective research framework. J Inf Technol 35(1):66-91

Wilhelm A, Heim A (2021) Expect an even hotter AI venture capital market in the wake of the Microsoft-Nuance deal. TechCrunch. https://techcrunch.com/2021/04/13/expect-an-even-hotter-ai-ven ture-capital-market-in-the-wake-of-the-microsoft-nuance-deal/. Accessed 28 July 2021

Wirtz BW, Pistoia A, Ullrich S, Göttel V (2016) Business models: origin, development and future research perspectives. Long Range Plan 49(1):36-54

Yin RK (2017) Case study research and applications: design and methods. Sage, Thousand Oaks 